Artigo recebido em 31.11.2018 / Aprovado em 06.02.2019

\title{
ASPECTOS JURÍDICOS DO MARKETING MULTINÍVEL
}

\author{
LEGAL ASPECTS OF MULTILEVEL MARKETING
}

\section{Anderneide Marques Silva ${ }^{1}$ Karine Mota ${ }^{2}$}

\section{RESUMO}

A economia mundial está em constante mudança, na qual estas vem agregando cada vez mais na sociedade. O marketing multinível pode ser considerado como um sistema que vem impactando de forma significativa essa economia, apesar de não ser um modelo de negócio tão recente, somente nos últimos anos que no Brasil esse sistema vem criando mais força, onde empresas que antes atuavam somente com a venda direta, passaram então a agregar o marketing multinível em seu sistema de negócio, majorando de forma expressiva seus resultados. Contudo, junto a essa ascendência, faz-se presente também outro sistema, o de pirâmide financeira. O fato é que, ainda há uma associação desses sistemas como se fossem a mesma coisa. Diante desse problema, este estudo tem por objetivo estabelecer as diferenças entre o marketing multinível e o sistema de pirâmide financeira, como também apontar os aspectos jurídicos que os permeiam. Para construção desse trabalho, foi realizado uma pesquisa de cunho bibliográfico e descritivo. Por fim, o que se pode concluir é que o marketing multinível é um sistema legal, ao contrário do sistema de pirâmide financeira, além de já ser considerado o negócio do século XXI.

Palavras-chaves: Negócio do Século XXI. Pirâmide Financeira. Renda Residual.

\begin{abstract}
The world economy is constantly changing, in which it is increasingly aggregating in society. Multilevel marketing can be considered as a system that has a significant impact on this economy, although it is not such a recent business model, only in the last few years that in Brazil this system has been creating more force, where companies that previously only worked with the direct sales, then began to aggregate multilevel marketing into their business system, significantly increasing their results. However,

\footnotetext{
${ }^{1}$ Acadêmica do Curso de Direito da Faculdade Católica do Tocantins. E-mail: anderneide.ams@hotmail.com

${ }^{2}$ Doutora em Ciências pela Universidade de São Paulo. Mestre em Direito pela Universidade de Marília. Bacharel em Direito pela Pontifícia Universidade Católica de Goiás . Docente na Faculdade Católica do Tocantins.E-mail: karine.mota@catolica-to.edu.br
} 
along with this ancestry, another system, the financial pyramid, is also present. The fact is, there is still an association of these systems as if they were the same thing. Faced with this problem, this study aims to establish the differences between multilevel marketing and the financial pyramid system, as well as to point out the legal aspects that permeate them. For the construction of this work, a bibliographic and descriptive research was carried out. Finally, what we can conclude is that multilevel marketing is a legal system, unlike the financial pyramid system, in addition to already being considered the business of the 21 st century.

Keywords: Business of the 21st Century. Financial pyramid. Residual income.

\section{INTRODUÇÃO}

O cenário atual do comércio mundial é reflexo de uma evolução nas relações existentes entre a oferta e a demanda, dentro de um processo ininterrupto gerado pela globalização. As organizações, dos mais variados países, inclusive o Brasil, passaram a ter uma visão holística no que tange a seu apresto para atender o mercado consumidor, tanto a nível nacional quanto internacional.

Nesse sentido, muitas empresas buscando ir ao encontro dessa necessidade cada vez mais imperativa, inclusive para as que já atuam nas vendas diretas, optam por se revolucionarem, passando assim a atuar no marketing multinível, sendo este também conhecido como marketing de rede, marketing de relacionamento e network de marketing.

O marketing multinível é um sistema de vendas em que os revendedores independentes ganham uma participação nos lucros adquiridos por ele e por sua rede de revendedores, tanto no que se refere as vendas quanto com o recrutamento de pessoas. Difere-se da venda direta, pois esta os ganhos se limitam apenas com as vendas dos produtos.

É importante mencionar que o marketing multinível é considerado com o negócio do século XXI (KIYOSAKI, 2012).

Basicamente, trata-se de uma economia conectada, onde um grupo de pessoas passam a obter vantagens com a venda para terceiros, recrutamento e também consumo próprio, se tornam seus próprios clientes, afinal por que comprar de 
"atravessadores" quando você pode obter vantagens comprando direto com preço de fábrica?

No entanto, dentro desse mecanismo, há também o que é conhecido como sistema de pirâmide financeira, o que vem a ser ilegal e muitas pessoas acabam associando com o sistema de marketing multinível. Assim, tem-se como problema o seguinte questionamento: o Sistema de marketing multinível é o mesmo que sistema de pirâmide financeira?

Empresas como Hinode, Herbalife, Amway e Mary Kay, atualmente constam como atuantes no marketing multinível. Já as empresas Avestruz Masters, Telexfree e Embrasystem - BBOM, foram constatadas como atuantes no sistema piramidal. Com esses exemplos, serão apontados no decorrer deste trabalho, na qual será contextualizado acerca desses dois sistemas, de modo a estabelecer as possíveis distinção entre eles. Como também é de extrema importância também adentrar acerca do aspecto jurídico na qual contempla o marketing multinível, de modo a constatar sua (in)legalidade.

Nesse sentido, por meio de uma pesquisa bibliográfica de caráter descritivo, este estudo tem por intuído apontar as distinções acerca do marketing multinível e o sistema de pirâmide financeira, além de abordar sobre os aspectos jurídicos que os permeiam.

\section{MARKETING MULTINÍVEL}

Em decorrências das mudanças que estão ocorrendo pelo mundo, diversas pessoas acabam buscando novos meios para impulsionar seu rendimento financeiro, ou seja, buscam uma renda extra, para não dependerem exclusivamente do trabalho convencional, ou na falta dele, ter uma atividade remunerada. Além disso, os anseios de muitas pessoas é querer dispor de mais tempo para a sua família, poder aproveitar melhor seu tempo, ter maior qualidade de vida e até mesmo, uma estabilidade financeira, que na maioria dos casos, o trabalho convencional não proporciona esse benefício.

Desse modo o Marketing Multinível ( $\mathrm{MMN}$ ) veio nas últimas décadas como proposta atender a essas outras necessidades. 


\subsection{HISTÓRICO}

É de suma importância abordar sobre o contexto histórico que constituiu o sistema de marketing multinível, essa forma de negócio se manifesta há séculos, na qual estudos apontam que, essa atividade ocorre desde a época de Moisés.

Aragão (2009) em seu livro "pequena história do marketing multinível", relata o estudo feito pelo Professor e Consultor de multinível Waldir Benevides que tem 30 anos de pesquisas sobre o sistema de rede, na qual o que mais the chamou a atenção foi por esse sistema ser desenvolvido desde os tempos bíblicos, por Moisés, com cerca de 3 milhões de pessoas.

"Moisés escolheu os 10 melhores entre os 3 milhões para fazer parte de sua primeira linha de líderes. Em multinível chamamos a estes da primeira linha de primeiro nível, ou diretos, por estarem diretamente ligados ao patrocinador" (ARAGÃO, 2009 P. $31)$.

"Estes dez também escolheram dez cada um, que somam então 100 pessoas no segundo nível. Os 100 colocaram cada um os seus 10 , completando 1000 pessoas no terceiro nível. $E$ assim por diante, em progressão, até chegarmos a 1 milhão de pessoas" (ARAGÃO, 2009 P. 31).

Em uma das histórias bíblicas no livro êxodo, escrita por Moisés, capítulo 18, versículo 21, é possível perceber o sogro de Moisés - Jetro, aconselhando-o a fazer sistematização do marketing multinível 10, 50, 100 e 1000 pessoas (BÍBLIA SAGRADA, 2009).

"Mas escolhe de entre os do povo uns tantos homens poderosos e tementes a Deus, nos quais haja verdade, e que aborreçam a avareza: e do número destes homens constitui a uns no governo de mil, a outros de cem; a outros de cinquenta, a outros de dez" (BÍBLIA SAGRADA, 2009, P. 79).

Nesse ponto pode-se observar a duplicação do marketing multinível, em que cada um vai duplicar a oportunidade para outros, da mesma forma que a pessoa que Ihe apresentou o negócio fez, esse fenômeno da duplicação é que diferencia a venda direta do marketing multinível. 
Segundo Aragão (2009), a evolução para o marketing de rede teve origem com as vendas diretas, porta-a-porta, boca-a-boca, por David McConnel em 1886, como vendedor de livros, na qual oferecia um frasco de perfume como brinde para os clientes que compravam os livros que vendia, de porta em porta, em New York, EUA. Com isso o negócio prosperou e surgiu então a Califórnia Perfumes. Então, em 1939 foi adotado o nome de AVON.

A partir de então, surgiram várias outras empresas nas quais utilizaram como base o negócio pioneiro da AVON e com inovações evoluíram em sistema, até atingir ao marketing multinível.

Segundo Aragão (2009), o ponto de partida do marketing multinível, foi instituído pelo médico, químico e industrial Carl Rehnborg em 1941, implementado na empresa Nutrilite.

Esse período foi considerado como a primeira onda do marketing multinível.

Até então só existia o mononível, então Dr. Carl foi muito mais além, a remuneração passou a atingir vários níveis, advindo daí o termo multinível (ARAGÃO, 2009).

O sistema de mononível também pode ser chamado de venda direta, no próximo tópico deste estudo será distinguido e conceituado acerca do mononível (venda direta) e multinível.

No multinível, o distribuidor passou a ganhar bônus também com as pessoas que seus diretos traziam para a empresa, o que foi uma revolução completa na época (ARAGÃO, 2009).

De acordo com Aragão (2009) com o multinível a empresa do Dr. Carl Rehnborg, teve um grande impulso. Contudo com a Segunda Guerra Mundial, progrediu a indústria bélica e tudo o que dissesse respeito à guerra, enfraquecendo então tudo o que não estivesse ligado a ela, inclusive a atividade de marketing multinível. Somente nos anos 50 , com a retomada do crescimento americano no pós-guerra, foi que o sistema de distribuição em multinível voltou a se expandir.

O sistema em níveis possibilita uma remuneração maior, tendo em vista que, enquanto no mononível o revendedor ganha apenas com suas vendas diretas, no multinível o ganho financeiro vai além de suas vendas, se estende também as vendas 
das pessoas da sua rede, ou seja as pessoas que ele trouxe para desenvolver 0 negócio da empresa, o ganho passa a ser baseado a sua produção e a produção da equipe que ele formar.

Em 1956, surgiu no EUA uma outra empresa em marketing multinível, a ShakeLee (ARAGÃO, 2009).

Em 1959, Jay Van Andel e Rich De Vos (trabalharam com o Dr. Carl Rehnborg nos anos 40 e 50) abriram na garagem da casa de um deles a empresa American Way Association, com a sigla Amway, com uma distribuição inicialmente de produtos de limpeza para o lar. O nome veio da expressão "American Way of Life" (estilo de vida americano). $O$ novo negócio foi tão bem que posteriormente compraram a empresa Nutrilite (ARAGÃO, 2009).

Aragão (2009) também destaca que nos anos 50, uma grande mulher nos EUA, já perto dos 60 anos de idade, criou a primeira oportunidade de multinível voltada para a mulher. Homem não entrava. Nas premiações por desempenho, os presentes eram joias caríssimas e também um prêmio inédito - um automóvel Cadillac todo cor-de-rosa. Ela foi a Sra Mary Kay (pseudônimo de Mary Kathlyn Wagner), fundadora em 1963 da empresa que leva o seu nome.

Conforme relatos históricos o sucesso do marketing multinível foi tão expressivo e crescente que nos anos 60 , ocorreu denúncias de que as empresas de multinível eram pirâmides disfarçadas, sendo levado esse caso a justiça.

Pereira (2014) destaca que ainda neste período, e após um tempo de choques e conturbações entre o modelo tradicional e o MMN, a Comissão Federal de Comércio norte-americano interviu e legalizou MMN como um negócio legítimo.

Até que em 1979 a Suprema Corte Americana deu um parecer favorável ao marketing multinível como sistema de comercialização, finalmente foi declarado como atividade perfeitamente legal e lícita. Então, a partir daí começou uma nova fase na história do multinível (ARAGÃO, 2009).

A partir desse ponto, pode-se considerar ou outro marco do marketing multinível, em que Pereira \& Maia (2014) considera como a segunda onda, que ocorreu de 1980 a 1989 , e foi marcada pelo surgimento de muitas empresas de MMN, muitas delas tinham suas instalações na própria residência do empresário, que por falta de estrutura 
organizacional, comprometia a organização, liderança e vender o seu negócio. Nesse período o sistema teve algumas dificuldades como o acúmulo de funções por parte dos distribuidores, e eles acabavam comprando mais produtos com o intuito desenvolvimento próprio da carreira dentro da empresa. Com isso, eles faziam cada vez mais um estoque próprio de mercadorias e não conseguiam eliminá-las (vendê-las).

O autor acima citado ainda menciona que a terceira onda ocorreu a partir 1990 a 1999, na qual passou a pensar na especialização desse tipo de negócio, sobretudo na área tecnológica; de mão de obra e sistemas informatizados de comunicação, junto a técnicas de gestão do momento para tornar o marketing multinível mais eficaz.

Paes (2002) afirma que essa ideia revolucionária chegou no Brasil em 1991 por meio da Amway, uma empresa americana que produz e comercializa artigos de consumo sem nenhum tipo de loja, franquia, equipe de vendas ou propaganda de massa; e depois foi seguida por tantas outras, tais como: Tupperware, Momentum Multinível, Pierre Alexander, Herbalife, Mary Kay, Contém 1g, One World, Victoria MR, etc.

Só no início dos anos 90 chegaram as primeiras empresas de marketing multinível no Brasil, que floresceram e duraram até hoje. Essas empresas já contemplação a Terceira Onda do MMN (Aragão, 2009).

Hage (2017) ainda fala de uma quarta onda (anos 2000) em que as empresas multinacionais investem em próprios $M M N$. Este impacto é em decorrência da imagem que o MMN construiu pelas empresas que trabalham com o sistema e o aplicam com seriedade, ficando consolidado no Brasil.

\subsection{DEFINIÇÃO E CARACTERÍSTICAS}

O Marketing Multinível é um negócio que está no Brasil há mais de duas décadas, mas ainda parecer se novo para muitas pessoas, causando várias dúvidas em quem está o conhecendo pela primeira vez. O marketing multinível (MMN) também é conhecido por outros nomes, como marketing de rede (MKR), marketing de relacionamento. 
Fernandes (2008) define o Marketing multinível como uma forma de distribuição que movimenta bens ou serviços legítimos com valor comercial, do fabricante diretamente para o consumidor, por meio de uma rede de revendedores independentes, na qual será proporcionado a eles comissões e prêmios que incidem não só nas suas vendas, mas também sobre toda a sua rede de vendas "downlines", elementos que pertencem à sua organização.

Segundo Alvarenga (2013), no modelo de MMN, o integrante da rede tanto pode ter ganhos na venda de produtos ou serviços, quanto por meio do recrutamento de novos participantes da rede. Sua receita é proporcional à receita gerada pelas vendas dos integrantes de sua rede, não sendo obrigatório realizar grande investimento em publicidade, em decorrência disso, esta verba é destinada à comissão e bônus aos seus vendedores e pertencentes à rede.

Nesse sistema, o consultor não ganha apenas suas vendas, mas também com o recrutamento de novos consultores e com a produção deles e dos demais que eles também recrutarem. A limitação do nível que haverá esse ganho varia de acordo com a empresa.

É importante destacar a diferença entre o MMN e a venda direta, ambos são uma forma de distribuição, contudo com algumas distinções.

Fernandes (2008) afirma que a venda direta pode ser efetuada sem utilizar o sistema MMN, chamado mononível, utilizado como uma venda única ou individual na qual um vendedor efetua vendas a um consumidor final e recebe por essas vendas, não tendo equipes de vendas associadas a ele.

Ou seja, na venda direta, os revendedores trabalham sozinhos e o ganho está relaciono a um percentual sobre a venda, sendo este percentual pré-estabelecido pela empresa. Nesse modelo, todos os revendedores estão no mesmo nível de porcentagem de lucro, a diferença de ganhos será na quantidade de pessoas que cada um alcançará com a venda direta.

Aqui é possível estabelecer uma diferença entre da venda direta com a aplicação do MMN e sem esse sistema, pois com o MMN além do ganho com a venda direta, tem a formação de equipes, na qual o ganho financeiro será tanto com base na entrada de novas pessoas no negócio, cadastradas direta ou indiretamente a ele, quanto com a 
produção (vendas) delas, ou seja, possibilita ao revendedor ter um ganho residual não somente com as pessoas cadastradas diretamente a ele, mas também com as pessoas cadastradas pelos que foram colocados na empresa por meio dele. Dessa forma, os ganhos tornam-se maiores, pois abrange níveis diferentes.

No que tange a extensão da rede de MMN, essa não tem uma predefinição em seu sistema, na qual deve ser definida pelas empresas que adotam essa forma de venda direta, procurando conciliar o limite de níveis horizontais e verticais com seu planejamento estratégico, modelo comercial e estrutura organizacional (PLATCHEK; ARBOITH; CARVALHO, 2015).

Os níveis de enquadramento da rede de MMN têm duas vertentes, a horizontal, (lateralidade), que remete as pessoas da rede ligadas diretamente ao primeiro distribuidor e a vertical, (profundidade), sendo as pessoas ligadas aos primeiros indicados horizontal ou lateralmente, em todos os níveis abaixo (ARAGÃO, 2009).

Assim a lateralidade é composta pelos indicados diretamente, onde esses duplicarão o negócio e começaram a trazer mais pessoas para a equipe, essas pessoas serão os indicados indiretamente, ou seja, que não são patrocinados diretamente por você, compondo assim a profundidade.

Aragão (2009) destaca que esse processo se fortalece em razão da empresa ao utilizar o marketing multinível em seu negócio, passa a aplicar o investimento, que por outro meio seria destinado para a promoção e para a propaganda na mídia, no programa de remuneração da cadeia de seus distribuidores. É a própria rede, disposta em níveis, que irá disseminar as informações pertinentes ao fabricante, promover a linha de produtos, perceber no cliente suas necessidades e preferências, possibilitando a organização maior atratividade perante o público-alvo.

Segundo Souza e Capdeville (2014) no MMN não é necessário ponto de vendas, muito menos o direcionamento dos produtos e serviços para os atacadistas ou varejistas, sem contar que não é gasto dinheiro em campanhas publicitárias de grande visibilidade, já que a propaganda do $M M N$ é de "boca a boca". Uma vez que não há gastos relativamente altos com campanhas publicitárias, o que tende a deixar mais caro o produto ou serviços, haja vista que o valor pago nestas campanhas teria que ser repassado aos produtos ou serviços. Dessa forma, o divulgador (distribuidor/consultor) 
compra produtos ou serviços mais baratos e repassa aos clientes finais com valores mais acessíveis.

Desse modo, pode-se perceber que no MMN ao invés da empresa investir em uma propaganda cara, com um ator famoso, que na maioria dos casos nem consome os produtos, ela opta em remunerar bem seus consultores para que eles façam a propaganda do negócio, dos produtos, para que eles promovam a empresa, pois dessa forma eles ganharão financeiramente com isso.

É importante ressaltar que no MMN, o revendedor é independente, na qual atua como um empresário por conta própria (FERNANDES, 2008).

Vale ressaltar que esse modelo de negócio tem por grande característica a forma de ganhos efetuados pelos revendedores/distribuidores, onde Fernandes (2008) distribui de três formas distintas:

a) Ganho na revenda dos produtos

b) Ganho nas vendas dos elementos da sua equipe

c) Participação nos lucros da empresa.

Além disso, Fernandes (2008) cita mais algumas das características que permeiam o MMN:

a) Baixo investimento inicial

b) Ganho por meritocracia

c) Ser um trabalhador por conta própria, mas não sozinho

d) Trabalhar em casa

e) Horários flexíveis

f) Apoio de liderança

g) Não existem limites geográficos para o desenvolvimento do seu negócio

h) Oportunidade de ampliar o seu campo de contatos e amizades

i) Não existe necessidade de elevados stocks

j) Entrega de mercadorias na casa do cliente

k) Contato pessoal e personalizado

I) Proporciona uma renda residual

Cabe frisar acerca dessa renda residual, onde Fernandes (2008) define como sendo uma renda continua ano após ano mesmo depois que a pessoa tenha terminado 
o trabalho. Tem-se como exemplo os compositores famosos, autores de bestsellers e investidores só estes tinham o privilégio da renda residual. As pessoas comuns só tiveram essa oportunidade com o MMN.

Essa renda residual é estimada por muitos, pois esta pode ser considerada a "grande aposentadoria digna" sem depender do que é fornecido pelo Estado, na qual a pessoa recebe ganho financeiro por um trabalho feito no passado, mas que continua gerando frutos atualmente sem que ela precise estar realizando aquele mesmo trabalho todos os dias, como é o que acontece no modelo tradicional de trabalho, na qual você vende suas horas para obter um ganho limitado mensal, se não for trabalhar será descontado no salário.

Kiyosaki (2012) complementa que não é apenas garantir renda hoje, amanhã é a semana seguinte; trata-se de garantir renda perpetuamente. Isso é renda residual: renda que continua chegando, mais e mais, muito tempo depois que você já terminou de gastar capital e esforço físico necessários para criar essa fonte de renda.

Inclusive é importante mencionar que Robert T. Kiyosaki é o autor de um dos best-sellers mais vendidos - Pai rico, pai pobre. Ou seja, ele já tem constituído a sua renda residual.

Robert T. Kiyosaki também escreveu outro livro que repercutiu estrondosamente - O negócio do século XXI, na qual ele relaciona esse negócio da seguinte forma: "Esse modelo de negócio é chamado marketing de rede" (KIYOSAKI, 2012, P. 35).

Assim para o autor, o ele considera o marketing multinível como a tendência de mercado, de fato o negócio do século atual.

"Hoje, o marketing de rede é reconhecido por muitos especialistas e homens de negócios bem-sucedidos como um dos modelos de negócio que mais cresce no mundo" (KIYOSAKI, 2012, P. 35).

Segundo Kiyosaki (2012), o objetivo nesse modelo de negócio não é uma pessoa vender um monte daquele produto, mas muitas pessoas sendo seus próprios melhores clientes (consumindo os próprios produtos da empresa), vendendo e atendendo a um número razoável de clientes e recrutando e mostrando a muitas outras pessoas como fazer o mesmo, ou seja, fazendo o processo de duplicação. 
Nesse ponto Kiyosaki (2012) justifica como sendo a razão pela qual uma pessoa queira construir um exército de representantes independentes: uma vez que você consegue, sabe o que tem em mãos? Um ativo que gera renda para você - renda residual.

Souza e Capdeville (2014) destacam que a função real do marketing é colocar algo novo no mercado que promova a qualidade de vida das pessoas, além de ocasionar à sociedade em geral um bem-estar. Em contrapartida desta satisfação, os acionistas das empresas majoram seus lucros significativamente.

As empresas que atuam no MMN mostram-se como agentes de solução para as necessidades das pessoas no seu dia a dia, além de oferecer um complemento financeiro na renda no final do mês e até mesmo um salário maior que a pessoa é acostumada receber. Com esta abordagem, as empresas que atuam neste segmento motivam seus divulgadores a trabalharem de forma direta com seus clientes bem como os futuros clientes que vão fazer parte da sua rede, sem contar do ciclo de compensação financeira tanto para os divulgadores com também para as empresas que atuam neste ramo (SOUZA E CAPDEVILLE, 2014 p. 5).

A Associação Brasileira de Vendas Diretas - ABVD (2018a), elenca as cinco razões para utilizar o marketing multinível, sendo eles:

a) Ter um horário flexível: é possível agregar essa atividade com outras, e definir o horário em que irá trabalhar.

b) Conhecer novas pessoas: todos dias o revendedor é cercado de diferentes pessoas, com a habilidade para se comunicar com o público se estabelece um bom relacionamento com o consumidor.

c) Garantir a independência financeira: o marketing multinível também representa muito mais do que uma renda extra: significa a independência financeira. Contudo no início é mais difícil, pois o consultor está ainda abrindo o seu mercado, mas com o desenvolvimento do negócio passa-se possível viver somente com o lucro das revendas.

d) Começar o próprio negócio com baixo investimento inicial: A revenda de produtos pode ser um meio de realização das pessoas que almejam ter seu próprio negócio. $O$ indivíduo tem a opção de escolher o que deseja vender, ganha o próprio dinheiro, administra o tempo e ainda obtém os lucros, tudo com esforço próprio. 
e) Receber bonificações por metas batidas ao utilizar marketing multinível: as empresas que atuam com o modelo de marketing multinível, geralmente bonificam seus revendedores de destaque. Os prêmios vão desde produtos da própria marca até viagens e veículos.

A ABVD (2018b), ainda complementa afirmando que o marketing multinível oferece uma maneira incrível para adicionar ainda mais de seus ganhos, por meio das pessoas que são cadastradas (downline). Com o desenvolvimento de uma downline sólida pode ser uma das formas mais lucrativas e gratificante para fazer uma rede de marketing multinível trabalhar para você.

Essas características do marketing multinível, na maioria dos casos, não estão presentes no modelo tradicional de emprego, o que leva muitos indivíduos a desenvolverem o MMN por visualizarem um futuro mais promissor, além de ser possível conciliar com outras atividades diárias, inclusive com o próprio modelo tradicional de emprego.

Souza e Capdeville (2014) afirmam que os divulgadores principiam pela oportunidade de uma renda extra no final do mês, contudo, no decorrer do tempo, começam a conhecer o segmento, suas ramificações, o modelo de execução ao ponto de se graduarem a níveis elevados, acarretando em uma expectativa positiva de seguir carreira nesta área que é ampla e rentável, tanto para as empresas que atuam no MMN como para os divulgadores.

Contudo há quem aproveita dessa ânsia em conseguir uma renda extra, uma flexibilidade no horário, ganho financeiro maior, independência financeira, entre outros benefícios, para utilizar de empresas ilegais "disfarçadas" de MMN, mas que na verdade trata-se de pirâmide, sendo este modelo ilegal. A diferença esses dois sistemas, MMN e pirâmide, será estabelecida no decorrer deste estudo.

Nesse sentido a ABVD (2018b) adverte que: “(...) fazer um pouco de pesquisa antes de assinar com uma empresa, é aconselhado. Isso irá garantir que você seja capaz de encontrar a solução mais rentável possível".

Essa pesquisa acerca da "melhor" empresa de marketing multinível para se ingressar, é importante até mesmo para fugir das empresas que atuam no sistema de pirâmides financeiras. 


\section{MARKETING MULTINÍVEL VERUS PIRÂMIDE FINANCEIRA}

É comum haver a confusão entre o MMN e o sistema de pirâmide, considerando que ambas trabalham a partir de ideias próximas, tendo em vista que os cooperadores procuram formar um grupo de pessoas. Contudo há diferenças significativas, a principal delas é que o MMN é legal e o sistema pirâmide é ilegal.

Souza e Capdeville (2014) destacam que as pessoas que não trabalham em criações e desenvolvimento de rede, sobretudo as que procuram dinheiro rápido neste segmento, ainda tem dificuldade em estabelecer a diferença entre pirâmide financeira e MMN, tanto por falta de informação como pela soma negativa de empresas e pessoas desonestas dentro do segmento de mercado.

As pirâmides financeiras buscam recrutar novos membros somente para dar ganhos para os que começam esta estrutura. Em contrapartida, o MMN é diferente, visto que tem produtos ou serviços para oferecer, paga impostos, ou seja, os pilares de uma sustentabilidade em longo prazo (SOUZA E CAPDEVILLE, 2014).

Então no MMN trata-se de um canal de distribuição de produtos e serviços, que gera lucros e rendas para os membros da rede na venda dos produtos e na formação da equipe. Já o sistema piramidal financeiro, visa principalmente a entrada de novas pessoas, considerando que a principal arrecadação e os lucros da empresa estão baseados no dinheiro da taxa de inscrição que os novos entrantes pagarão, independentemente de ter a oferta de produto.

O PROCON - Proteção ao Consumidor (2010) esclarece que o golpe da pirâmide é um artifício comercial não sustentável que paga valores pelo recrutamento de outras pessoas para o esquema, sem a entrega de qualquer produto ou serviço, sendo esse sistema considerado ilegal pelo Código de Defesa do Consumidor.

O que torna o sistema de pirâmide financeira insustentável é pelo fato que, em um determinado momento, os atuais participantes não conseguirão encontrar outras pessoas para colocar abaixo de seus níveis, fazendo com que o esquema piramidal não possua mais fonte de renda, fazendo com que os últimos entrantes fiquem sem o prometido retorno de seus investimentos (PLATCHEK; ARBOITH; CARVALHO, 2015). 
O sistema de pirâmide financeira utiliza por vezes, até a venda de um determinado produto ou serviço como disfarce, será dado exemplo dessas empresas no tópico a seguir, mas os envolvidos são remunerados sobretudo pela indicação de outros participantes, desconsiderando a venda real do produto. Contudo, chega a um determinado momento, em que o valor do dinheiro desse recrutamento não é suficiente para cobrir as despesas, o que acarreta em atrasos de pagamentos, até se tornar insustentável e causar prejuízo para quem investiu.

Platchek; Arboith; Carvalho, (2015), estabelece outra diferença importantíssima entre esses dois sistemas, que se refere a certificação junto a ABEVD - Associação Brasileira de Empresas de Vendas Diretas:

Portanto, a fim de distinguir com que modelo a empresa trabalha, um parâmetro relevante que pode auxiliar a identificação de empresas de Marketing Multinível é o reconhecimento e o registro da $A B E V D$, pois para associar-se à $A B E V D$ a empresa tem que se adequar aos Códigos de Ética da entidade, que orienta a conduta diante dos consumidores, dos vendedores diretos e entre as empresas. Vale lembrar que, além deste ponto, a análise do mercado, a história e as tendências das organizações são igualmente importantes para obter-se um panorama, esquivando-se dos riscos, evidenciando as oportunidades que apresentam mais benefícios e vantagens aos interessados e a todos os envolvidos no negócio (PLATCHEK; ARBOITH; CARVALHO, 2015 p.7).

É importante destacar que a ABVD é uma organização atuante há mais de 30 anos no Brasil, na qual tem por responsabilidade regulamentar as normas atinentes a vendas diretas e, consequentemente, do marketing multinível. Diante disso, essa certificação apontada pelos autores acima, acaba dando maior credibilidade para a empresa, no que tange ao desenvolvimento do sistema de marketing multinível junto com os seus distribuidores/consultores, sendo esse um dos critérios para o indivíduo analisar, com o intuito de se certificar quanto a seriedade e legalidade da empresa.

\subsection{CASOS DE PIRÂMIDES FINANCEIRAS E EMPRESAS DE MARKETING MULTINÍVEL}

Nessa etapa do estudo serão citados alguns casos de empresas que foram constatadas como atuantes no sistema de pirâmides financeira e das empresas que atuam com o marketing multinível. 
2.1.1. Empresas em sistema de pirâmides financeiras

\section{a) Avestruz Master}

Segundo Ayres (2013), a Avestruz Master foi fundada em Goiânia, a proposta era feita para que as pessoas adquirissem os avestruzes, que quando completassem 18 meses de vida, teriam um retorno de $10 \%$ sobre a aplicação até o mês que a ave fosse readquirida pela empresa.

Esse esquema teve uma repercussão em todo o Brasil. Foram descobertas várias irregularidades, dentre elas, houve superior a 600 mil animais vendidos enquanto só tinham 38 mil. Em 2005 a pirâmide caiu, ficou insustentável, em 2010 a Justiça Federal condenou os donos da Avestruz Master a indenizar os 40.000 investidores, em 100 milhões de reais e penas de 12 a 13 anos de prisão. O prejuízo total dos investidores que foi estimado em 1 bilhão de reais (AYRES, 2013).

b) Telexfree

A empresa Telexfree., na qual vendia planos de minutos de telefonia de voz por meio da internet (VoIP na sigla em inglês), teria montado um esquema de pirâmide, em que cada pessoa adquire um "pacote" que recompensa os membros acima na cadeia. Esse novo membro, por sua vez, ganha dinheiro cadastrando outras pessoas para o sistema (GASPARIN, 2013).

Cada conta custa US\$49,90 (cerca de $R \$ 100$ ). Na medida que a pessoa se torna um "divulgador", ele pode comprar pacotes de contas com desconto, cujo interessado deve pagar uma taxa de adesão de US\$ 50 (cerca de $R \$ 100$ ). Um pacote com 10 contas custa US\$ 289 (quase $R \$ 600$ ) e um com 50 contas custa US\$ 1.375 (cerca de $\mathrm{R} \$ 2,8 \mathrm{mil}$ ). Os valores são estabelecidos em dólares porque a prestadora de serviços, a Telexfree, fica nos Estados Unidos. No Brasil, a Ympactus faz a gestão administrativa (GASPARIN, 2013).

Gasparim (2013), afirmou ainda que, a Secretaria de Acompanhamento Econômico (Seae) do Ministério da Fazenda também apontou não foi evidenciada a parceria entre a Ympactus Comercial Ltda. ME, conhecida pelo nome fantasia Telexfree, e operadoras de telefonia móvel ou fixa - o que seria indispensável para 
assegurar a prestação do serviço de VolP, conforme ofertado pela empresa. Além disso, a descrição das atividades econômicas principal e secundária da empresa Telexfree, não permitem a praticar atividades de comércio.

c) Embrasystem - BBOM

Em agosto de 2013 foi ajuizada pelo Ministério Público Federal (MPF) em Goiás uma ação de civil pública, face a empresa as empresas Embrasystem - Tecnologia em Sistemas, Importação e Exportação e BBrasil Organizações e Métodos (Bbom) por prática ilegal de pirâmide financeira, no dia 13 de dezembro de 2017 obteve a sentença judicial com a condenação (GOIÁS,2017).

De acordo com Martins (2017), o produto que supostamente "sustentaria" o negócio da BBom é um rastreador de veículos, o que na verdade, seria apenas uma "isca" para recrutar novos associados. Os integrantes são remunerados pela indicação de novos participantes no negócio, sem considerar a quantia gerada pela venda dos produtos, o que caracteriza sistema de pirâmide financeira.

Os interessados se associavam por meio de um pagamento de $R \$ 60,00$, sendo essa uma taxa de cadastro, mais uma taxa de adesão, que variava de $R \$ 600$ a $R \$ 3$ mil, de acordo com o plano escolhido. A bonificação oferecida pela empresa aumentava na medida que crescia o número de novos integrantes (MARTINS, 2017).

$\mathrm{Na}$ decisão, as empresas Embrasystem e da BBrasil teve a dissolução compulsória e, como consequência, suas liquidações judiciais, foi declarada ainda, a nulidade de todos os contratos feitos no âmbito do "Sistema Bbom-UNEPXMIL", no período anterior a 5 de agosto de 2013. Os réus (pessoas jurídicas e físicas) foram condenados ao reembolso dos valores pagos pelos consumidores/associados/investidores que tenham aderido a quaisquer dos planos disponibilizados pelo "Sistema Bbom" até o referido período, além do pagamento de indenização no valor de $\mathrm{R} \$ 100$ milhões, por danos morais e coletivos, na qual serão revertidos ao Fundo de Defesa de Direitos Difusos (GOIÁS,2017).

Considerando os exemplos mencionados de casos que já foram configurados pela justiça como atuantes no sistema de pirâmide financeira, é possível chegar a um ponto em comum entre eles que, as pessoas são cadastradas mediante a um pagamento para se associar ao sistema, onde tem um produto/serviço, mas que este 
trata-se apenas de um disfarce, cuja a recompensa maior é advinda com o recrutamento de outras pessoas - que, por sua vez, deverão recrutar outras.

O fato é que, no final, esse negócio se torna insustentável, pois o produto de fato não existe ou é insuficiente, o que muitas vezes nem é comercializado, e chega a um determinado momento que não haverá novos cadastros, com isso o dinheiro percorre a pirâmide, e somente os indivíduos que estão na ponta do negócio, que entraram primeiro, que são os idealizadores, acabam ganhando, tendo em vista que as pessoas que estão na base do esquema aderem o plano, mas não são capazes de trazer aos sistema novos seguidores.

\subsubsection{Empresas de marketing multinível}

Neste ponto cabe mencionar empresas que atualmente se encontram atuando no sistema de marketing multinível, dentre elas pode-se citar: Hinode, Boulevard Monde, Amway, Herbalife, Mary Kay, Jeunesse, Polishop, 19 Life, UP! Essência, etc.

Essas empresas mencionadas têm em comum fatores que as caracterizam como atuantes no sistema de marketing multinível, ao invés de sistema pirâmide financeira como nos exemplos apontados no item anterior dessa pesquisa, os seguintes fatores:

a) Possuem um site oficial apontando de forma clara sua procedência;

b) Independentemente da oportunidade de negócio na construção de rede/equipe, trabalha na distribuição de produtos com valor real percebido por clientes finais, na qual não façam parte da rede;

c) Tais produtos têm valor e demanda comercial;

d) Conforme é possível verificar no site da ABVD (2018c), as empresas citadas então entre as 50 (cinquenta) empresas que são associadas a ABVD.

e) Mesmo para as pessoas que não atuam com a parte de construção de rede/equipe, as empresas oferecerem oportunidades de lucro/comissão sobre vendas;

f) Tem pelo menos 3 anos de atuação no Marketing de Rede.

Para Content (2017), as empresas de marketing multinível mais importantes no Brasil são: 
a) Hinode: Existe há mais de 30 anos, mas apenas recentemente aderiu ao marketing multinível, passando a se tornar conhecida por consultores e consumidores de cosméticos e de produtos de beleza e de emagrecimento. Os revendedores e comerciantes autônomos obtêm o produto com $50 \%$ de desconto, para vender por preço tabelado ou consumir os produtos.

b) Herbalife: tem como jargão utilizado por seus distribuidores "Quer emagrecer? Pergunte-me como!". A empresa tem por foco a linha de bem-estar.

c) Amway: Faz parte do Grupo Alticor, com uma ampla gama de produtos oferecidos por um baixo preço, excelente qualidade, feitos de compostos orgânicos, os seus produtos vão desde artigos de nutrição até antialérgicos e produtos profissionais para salão de beleza.

d) Mary Kay: Destinada exclusivamente para o público feminino, tem por "carro chefe" a linha de maquiagem. O preço é um pouco maior do que das concorrentes como Avon e Natura, contudo de extrema qualidade e durabilidade.

Não pode deixar de ser mencionado os tradicionais carros rosas, quando uma revendedora da marca ganha por atingir o nível de diretora na empresa.

e) Boulevard Monde: existe há 15 anos, mas adotou marketing multinível apenas em 2015. A empresa também oferece aos seus distribuidores $50 \%$ de desconto nos produtos.

Dentre as empresas mencionadas pelo autor acima citado, é importante destacar a hinode, pois esta é a única empresa de origem brasileira, onde foi criada no ano de 1988, mas somente no ano de 2008 foi sua inserção no marketing multinível.

Segundo o com Scheller (2017), do O Estado de S. Paulo, até a inserção da Hinode no marketing multinível, o faturamento da empresa tinha estacionado em $R \$ 8$ milhões ao ano. Então em 2008, veio a implantação do sistema de marketing multinível na empresa, apesar da certeza do caminho, ele se revelou árduo: a receita logo caiu $90 \%$. Nos três anos seguintes, a família foi obrigada a vender bens para sustentar a empreitada.

Contudo em 2012, o presidente da empresa Sandro Rodrigues juntamente com os outros diretores, se deu conta do problema durante uma reunião: os antigos 
vendedores não tinham o perfil para o modelo multinível, que exigia líderes de equipes. A partir daí a realidade da empresa mudou de forma expressiva (SCHELLER, 2017).

"Apostando no poder das classes C e D, a Hinode fechará 2017 com 750 mil consultores e receita de $R \$ 2,6$ bilhões. De mera desconhecida, passou a séria ameaça a gigantes da venda direta, como Natura e Avon" (SCHELLER, 2017).

Figura 02: Crescimento da empresa Hinode 2014 a 2017

\section{Revendedores}

EM MILHARES DE PESSOAS

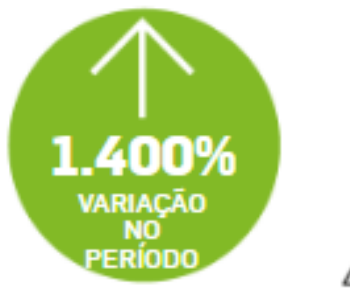

460

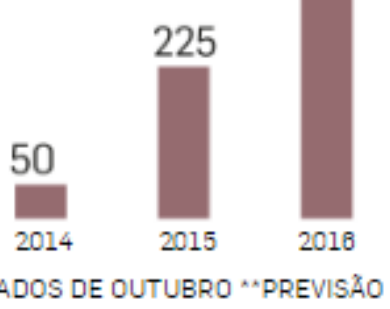

\section{Faturamento}

EM MILHOES DE REAIS

750

$1.430 \%$

VARIAÇĀO

PERIODO

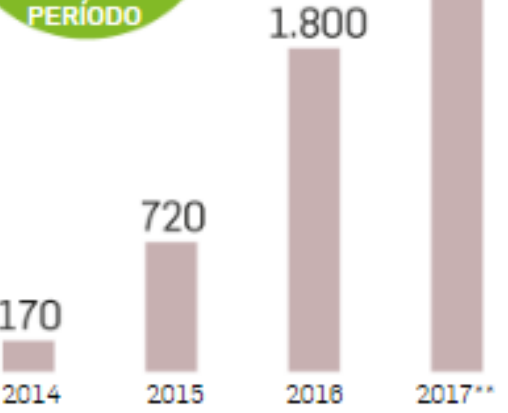

Fonte: Scheller (2017)

Desempenha muito forte a venda direta, incentivando seus consultores na venda e consumo dos produtos, como também no sistema de construção de equipe, com bonificações na qual também contempla carros e viagens.

Atualmente a empresa atua nos seguimentos de cosméticos, perfumaria, linha infantil, bem-estar, alta performance, maquiagem, higiene pessoal e aromatizantes de ambiente.

A Hinode ganhou as seguintes premiações de 2015 a 2017:

Quadro 01: Premiações Hinode 2015 a 2017

\begin{tabular}{|c|l|l|l|}
\hline ANO & \multicolumn{1}{|c|}{ ORGANIZAÇÃO } & \multicolumn{1}{c|}{ PREMIAÇÃO } \\
\hline 2015 & $\begin{array}{l}\text { Associação Brasileira da indústria de } \\
\text { Higiene Pessoal, Perfumaria e e } \\
\text { Cosmético - ABIHPEC }\end{array}$ & $\begin{array}{l}\text { Melhor criação perfumística: Produto } \\
\text { Empire }\end{array}$ & \\
\hline 2016 & Associação Brasileira da indústria de & Empresa do ano \\
\hline
\end{tabular}




\begin{tabular}{|c|c|c|}
\hline & $\begin{array}{l}\text { Higiene Pessoal, Perfumaria e } \\
\text { Cosmético - ABIHPEC }\end{array}$ & \\
\hline 2016 & $\begin{array}{l}\text { Associação dos Dirigentes de Vendas } \\
\text { e Marketing do Brasil - ADBV }\end{array}$ & $\begin{array}{l}\text { Personalidade em vendas: } \\
\text { Rodrigues, CEO da Hinode }\end{array}$ \\
\hline 2016 & $\begin{array}{l}24^{\circ} \text { Edição do Prêmio Atualidade e } \\
\text { Cosmético }\end{array}$ & $\begin{array}{l}\text { - Melhor criação Perfumística Latino- } \\
\text { Americana Feminina: Produto Grace } \\
\text { Midgnhith da América Latina } \\
\text { - Profissional do Ano: Sandro Rodrigues, } \\
\text { CEO da Hinode } \\
\text { - Hall da Fama: Adelaide Rodrigues e } \\
\text { Francisco Rodrigues, fundadores da } \\
\text { Hinode }\end{array}$ \\
\hline 2017 & $\begin{array}{l}25^{\circ} \text { edição do Prêmio Atualidade e } \\
\text { Cosmético }\end{array}$ & Empresa do ano \\
\hline 2017 & $\begin{array}{l}\text { Associação Brasileira de Marketing \& } \\
\text { Negócios - ABMN }\end{array}$ & $\begin{array}{l}\text { Personalidade Empresarial do Ano: Sandro } \\
\text { Rodrigues, CEO da Hinode. }\end{array}$ \\
\hline
\end{tabular}

Fonte: ABIHPEC (2015); ABIHPEC (2016); ABMN (2017); ADVB (2017); COSMETICANEWS (2017).

Sem dúvida, essas premiações bem como a própria empresa Hinode, acabam se destacando em meio a grandes outras empresas relacionadas ao marketing multinível como também outras que atuam somente com a venda direta, mas nos mesmos seguimentos de produção.

\section{LEGISLAÇÃO REGULAMENTAR DO MARKETING MULTINÍVEL}

No Brasil, o sistema de marketing multinível tem no âmbito legal uma deficiência devido à falta de legislação específica para esse sistema de distribuição. Contudo, conforme já mencionado neste estudo, a prática desse negócio não é vedada, muito menos ilícito, sendo ele submetido as demais normas atinentes às empresas em geral.

A princípio cabe mencionar o que preconiza a Lei maior - Constituição Federal de 1988, em seu art. 170, IV, VIII e parágrafo único:

Art. 170 da CF. A ordem econômica, fundada na valorização do trabalho humano e na livre iniciativa, tem por fim assegurar a todos existência digna, conforme os ditames da justiça social, observados os seguintes princípios:

(...)

IV - livre concorrência;

$(\ldots)$

VIII - busca do pleno emprego;

$(\ldots)$ 
Parágrafo único. É assegurado a todos o livre exercício de qualquer atividade econômica, independentemente de autorização de órgãos públicos, salvo nos casos previstos em lei (BRASIL, 1988).

Assim, pode-se afirmar que a Constituição federal de 1988 já qual assegura toda e qualquer prática de atividade comercial e empreendedora lícitas, mas isso mediante a existência da prestação de serviço ou comercialização de produtos.

No que se refere a relação de emprego de um distribuidor de marketing multinível, não há o que se falar que exista tal relação - empregado e empregador, tendo em vista que, para se configurar no polo de empregado, o mesmo precisa exercer atividade não eventual, subordinada e mediante salário; na relação de empregador este assalaria e dirige a prestação pessoal de serviço bem como a admissão das pessoas.

Além disso, é importante mencionar a Lei no 1.521 de 26 de dezembro de 1951, na qual se baseia na fraude contra a economia popular, onde pune as pessoas que tentam obter benefício sobre outras pessoas de forma ilícita:

Art. $2^{\circ}$. São crimes desta natureza:

IV - negar ou deixar o fornecedor de serviços essenciais de entregar ao freguês a nota relativa à prestação de serviço, desde que a importância exceda de quinze cruzeiros, e com a indicação do preço, do nome e endereço do estabelecimento, do nome da firma ou responsável, da data e local da transação e do nome e residência do freguês;

$(\ldots)$

IX - obter ou tentar obter ganhos ilícitos em detrimento do povo ou de número indeterminado de pessoas mediante especulações ou processos fraudulentos ("bola de neve", "cadeias", "pichardismo" e quaisquer outros equivalentes); (...)

Pena - detenção, de 6 (seis) meses a 2 (dois) anos, e multa, de dois mil a cinquenta mil cruzeiros (BRASIL, 1951).

Essa Lei mencionada, não cita explicitamente o sistema de pirâmide financeira. Contudo, pelo que teor que ela transmite, pode-se considerar esse sistema como um dos processos fraudulentos, baseado o que já foi discutido a respeito do modelo piramidal.

Na esfera penal, é possível também mencionar o Código Penal brasileiro, mas nesse caso, a interpretação seria estreita para contemplar o Marketing Multinível, baseando a punição sob o escudo do estelionato, quando houver empresários formando e anunciando o negócio de forma a causar dano aos consumidores, conforme o art. 171 do referido código: 
Art. 171 - Obter, para si ou para outrem, vantagem ilícita, em prejuízo alheio, induzindo ou mantendo alguém em erro, mediante artifício, ardil, ou qualquer outro meio fraudulento:

Pena - reclusão, de um a cinco anos, e multa (BRASIL, 1940).

Tendo em vista, a crescente mudança no cenário econômico, com o surgimento ou migração de muitas empresas para o sistema de marketing multinível no Brasil, se tornou ainda mais imperativo a necessidade de que seja instaurada uma lei específica para contemplar essa forma comercial.

Nesse sentido, foi elaborado Projetos de Lei - PL para regulamentar o marketing multinível, sendo eles:

a) PL 6.170/13: "Regulamenta as atividades de operador de Marketing Multinível no Brasil" (BRASIL, 2013a).

b) PL 6.667/13: "Regulamenta o marketing multinível, estabelece normas de proteção aos empreendedores de marketing multinível, e dá outras providências" (BRASIL, 2013b).

c) PL 7.288/14: "Regulamenta a atividade de marketing multinível, distinguindo-a do crime de "pirâmide financeira", e dá outras providências" (BRASIL, 2014).

d) PL 6.775/13 Regulamenta a atividade econômica denominada marketing multinível; fixa requisitos para funcionamento das empresas brasileiras e estrangeiras, do segmento, no território nacional; estabelece normas de proteção aos empreendedores de marketing multinível; acrescenta o art. 20-A à Lei no 7.492, de 16 de junho de 1986, e o art. 5-A à Lei no 8.137, de 27 de dezembro de 1990, para tipificar a "pirâmide financeira" e condutas equivalentes nas leis de crimes contra a ordem econômica e contra o sistema financeiro nacional, revogando o inciso IX do art. $2^{\circ}$ da Lei $n^{\circ} 1.521$, de 26 de dezembro de 1951, com o consequente agravamento das penas, e dá outras providências (BRASIL, 2013c).

Contudo, nesses últimos 5 (cinco) anos, desde que foi criado esses Projetos de Lei, o cenário no marketing multinível no Brasil vem crescendo de forma mais acelerada no mercado. Entretanto, ainda se encontram para aprovação no plenário. Assim que forem de fato legalizado esse modelo de negócio, será um grande ganho para o cenário comercial. 


\section{CONSIDERAÇÕES FINAIS}

O marketing multinível é um sistema legal de vendas diretas como também de recrutamento de pessoas, mas que tem por base uma empresa consolidada com produtos de valor comercial, na qual emprega o relacionamento dos seus distribuidores independentes para estreitar o caminho de consumo entre os fabricantes e os consumidores finais.

Esse sistema possibilita o crescimento pessoal e profissional e forma grandiosa, como também a construção de uma renda residual, Robert T. Kiyosaki também defende essa mesma ideia. Contudo é importante fazer um mero questionamento: Por que Robert T. Kiyosaki escritor de um best-sellers, sendo este uma de suas rendas residuais, indicaria o modelo de marketing multinível como sendo o negócio do século $\mathrm{XXI}$ ao invés de uma outra forma de negócio por exemplo escrever um best-sellers?

O fato é que diante de muitos estudos, pesquisas realizadas pelo autor, esse modelo de negócio trata-se de algo revolucionário no mercado, meio de obter uma renda residual por meio da construção de rede, as pessoas serão clientes dos próprios produtos que representam, além da própria venda e recrutamento de pessoas que farão a mesma coisa. Além disso, é importante refletir do que seria mais duplicável de ser feito? Escrever um best-seller ou construir uma rede de consumidores e representantes independentes?

Este estudo também trouxe a necessidade de se romper paradigmas no que se refere a confusão ainda feita por muitas pessoas em que, o marketing multinível referese a um tipo de pirâmide financeira. O fato é que ambos são distintos, o que deve ser analisado é, se o objetivo da empresa é apenas trabalhar o recrutamento por meio de um investimento financeiro, sem considerar a existência ou não de um produto que seja comerciável. Com essa análise, com certeza chegará a conclusão do sistema em que a empresa atua: MMN ou Pirâmide financeira.

No que tange a relações jurídicas, apesar de não haver uma legislação específica, mas que é amparada por outras existentes, o MMN é legal, e permite que continue a se desenvolver e ajudar os envolvidos a construir o seu empreendimento, 
mas a instauração de uma legislação específica com certeza traria maior segurança jurídica, bem como mitigaria a relação do marketing multinível com o sistema piramidal.

Por fim, o fato de ter um amparo legal, bem como opiniões de várias pessoas de seguimentos diferentes, sendo até mesmo multimilionária que entende do mercado atual, como por exemplo Robert T. Kiyosaki, faz ter maior segurança com relação ao sistema MMN, distanciando de vez a possibilidade de ser o mesmo que pirâmide financeira.

\section{REFERÊNCIAS}

Associação Brasileira da Indústria de Higiene Pessoal, Perfumaria e Cosmético ABIHPEC. Prêmio ABIHPEC-Beleza Brasil: conheça os vencedores da edição 2015 Disponível em: <http://abihpec.org.br/belezabrasil/2014/premio-abihpec-beleza-brasilconheca-os-vencedores-da-edicao-2015/>. Acessado em 10 mai. 2018.

. Confira os vencedores do Prêmio Abihpec Beleza-Brasil 2016. Disponível em: <http://abihpec.org.br/belezabrasil/2014/confira-os-vencedores-premioabihpec-beleza-brasil-2016/>. Acessado em 10 mai. 2018.

Associação Brasileira de Marketing \& Negócios - ABMN. Personalidade empresarial do prêmio marketing contemporâneo 2017. Disponível em: $<$ http://premiomktcontemporaneo.com.br/personalidade-empresarial-do-premiomarketing-contemporaneo-2017/>. Acessado em 10 mai. 2018.

ABVD - Associação Brasileira de Vendas Diretas. 5 razões para utilizar o Marketing Multinível. 2018a. Disponível em: <http://www.abevd.org.br/noticias-publicacoes/5razoes-para-utilizar-o-marketing-multinivel/>. Acessado em 10 mai. 2018.

Marketing de Rede: uma forma de encontrar o sucesso em sua vida. 2018b. Disponível em: <http://www.abevd.org.br/noticias-publicacoes/marketing-de-rede-umaforma-de-encontrar-o-sucesso-em-sua-vida/>. Acessado em 10 mai. 2018.

Empresas associadas. 2018c. Disponível <http://www.abevd.org.br/empresas-associadas/>. Acessado em 10 mai. 2018.

Associação dos Dirigentes de Vendas e Marketing do Brasil - ADBV. Personalidade de Vendas. Disponível em: <http://www.advb.org/2012/07/23/personalidade-de-vendas/>. Acessado em 10 mai. 2018.

AYRES, Marcela. 6 golpes financeiros que enganaram milhares de investidores. Disponível em: <http://exame.abril.com.br/seu-dinheiro/noticias/6-golpes-financeirosque-enganaram-milhares-de-investidores?p=5>. Acesso em: 12 mar. 2013. 
ALVARENGA, Darlan. Saiba como identificar indícios de pirâmide para não cair em golpes. Disponível em: <http://www.g1.globo.com/economia/noticia/2013/07/saibacomo-identificar-indicios-de-piramide-para-nao-cair-em-golpes.html>. Acesso em: 28 mar. 2017.

ARAGÃO, Paulo de Tarso. Pequena história do marketing multinível. Recife: COMUNIGRAF, 2009.

BÍBLIA SAGRADA / [Traduzida em português da Vulgata Latina po PE. Antônio Pereira de Figueiredo]. São Paulo: DCL, 2006.

BRASIL. Lei o 1.521, de 26 de dezembro de 1951. Crimes contra a economia popular. Rio de Janeiro, dez, 1951. Disponível em: <http://www.planalto.gov.br/ccivil_03/leis/L1521.htm>. Acessado em: 15 abr. 2018.

. Câmara dos deputados. PL 6.170/13. 2013a. Disponível em: <http://www.camara.gov.br/proposicoesWeb/fichadetramitacao?idProposicao=613863>. Acessado em 10 mai. 2018.

Câmara dos deputados. PL 6.667/13. 2013b. Disponível em: http://www.camara.gov.br/proposicoesWeb/fichadetramitacao?idProposicao=598956\&or $\mathrm{d}=1$. Acessado em 10 mai. 2018.

Câmara dos deputados. PL 6.775/13. 2013b. Disponível em: <http://www.camara.gov.br/proposicoesWeb/fichadetramitacao?idProposicao=601326 $>$. Acessado em 10 mai. 2018. <http://www.camara.gov.br/proposicoesWeb/fichadetramitacao?idProposicao=609018>. Acessado em 10 mai. 2018.

. Lei $N^{\circ} 2.848$, de 7 de dezembro de 1940. Código Penal. Disponível em: <http://www.planalto.gov.br/ccivil_03/decreto-lei/Del2848compilado.htm>. Acessado em: 10 mai. 2018.

Constituição da República Federativa do Brasil de 1988. Disponível em: <http://www.planalto.gov.br/ccivil_03/constituicao/constituicao.htm>. Acessado em: 10 mai. 2018.

CONTENT, Redator Rock. Conheça 5 empresas de marketing multinível no Brasil. Disponível em: <https://marketingdeconteudo.com/marketing-multinivel-no-brasil/>. Acessado em 10 mai. 2018. 
COSMETICANEWS. Conheça os vencedores de toda a história do evento. Disponível em: <http://cosmeticanews.com.br/premioatualidadecosmetica/vencedores.html>. Acessado em 10 mai. 2018.

FERNANDES, Rafael Filipe Guerreiro da Silva. Como alcançar o sucesso no marketing multinível. 2008.2 Disponível em: <https://ria.ua.pt/bitstream/10773/1603/1/2008001815.pdf>. Acessado em 28 mar. 2017.

GASPARIN, Gabriela. Entenda o caso Telexfree. Disponível em: <http://g1.globo.com/economia/noticia/2013/03/entenda-o-caso-telexfree.html>. Acessado em 01 mai. 2018.

GOIÁlS. Ministério Público do Estado de Goiás. Embrasystem - BBOM. Disponível

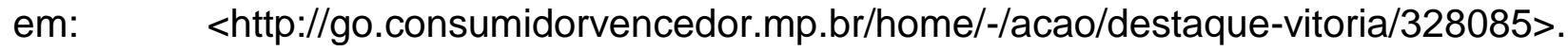
Acessado em: 01 mai. 2018.

HAGE, Adriana. Marketing Multinível Sem Pré Conceitos. Disponível em: <http://www.livrosdigitais.org.br/baixar-livro/39075GMY8922FX>. Acessado em 22 mar. 2017.

MARTINS, Vanessa. Justiça determina dissolução da BBom e pagamento de R\$ 100 milhões por esquema de pirâmide. Disponível em: <https://g1.globo.com/go/goias/noticia/justica-determina-dissolucao-da-bbom-epagamento-de-r-100-milhoes-por-esquema-de-piramide.ghtml>. Acessado em: 01 mai. 2018.

PAES, Francisco José Coutinho. Multinível: o retrato falado de uma megatendência. 2002. Disponível em: <http://docplayer.com.br/6546254-Multinivel-o-retrato-falado-deuma-megatendencia.html>. Acessado em: 15 mar. 2017.

PEREIRA. Américo; MAIA, Virgínia Helena Lins. Marketing multinível versus pirâmide financeira: um estudo de caso no Brasil. 2014. Disponível em: $<$ https://jus.com.br/artigos/31318/marketing-multinivel-versus-piramide-financeira-umestudo-de-caso-no-brasil/1 >. Acessado em 15 mar. 2017.

PLATCHEK, Renata Granemann Bertoldi; ARBOITH, Amanda Barrozo; CARVALHO, Luciano Augusto Alves De. Marketing multinível no brasil. 2015. Disponível em $<$ http://siaiap32.univali.br/seer/index.php/cccg/article/download/8228/4619>. Acessado em: 22 mar. 2017.

PROCON, Proteção ao Consumidor. Esquema da pirâmide: proteja-se - Grupo que prometia casa própria é fechado por aplicar golpe. Riberirão Preto, 2010. Disponível em: $<$ http://www.

ribeiraopreto.sp.gov.br/scidadania/procon/noticias/golpe_da_piramide_proteja_se.pdf>. 
Acesso em: 22 mar. 2017.

KIYOSAKI, Robert Toru. O negócio do século XXI / Robert Kiyosaki com John Fleming e Kim Kiyosaki ; tradutora Eliana Bussinger. - Rio de Janeiro : Elsevier, 2012.

SCHELLER, Fernando. Focada nas classes C e D, Hinode cresce e incomoda as gigantes Natura e Avon. Disponível em: <http://economia.estadao.com.br/noticias/geral,focada-nas-classes-c-e-d-hinodecresce-e-incomoda-as-gigantes-natura-e-avon,70002098249>. Acessado em: 10 mai. 2018.

SOUZA, José Marques de; CAPDEVILLE, Adrienne. Marketing Multinível. 2014. Disponível em: <http://revista.faculdadeprojecao.edu.br/index.php/Projecao1/article/viewFile/406/363>. Acessado em 22 mar. 2017. 